\title{
Temperature and development of central European species of Amara (Coleoptera: Carabidae)
}

\author{
PAVEL SASKA and Alois HONĚK \\ Research Institute of Crop Production, Drnovská 507, CZ 16106 Praha 6 - Ruzyně, Czech Republic, e-mail: saska@vurv.cz
}

Key words. Amara aenea, A. familiaris, $A$. similata, $A$. ovata, A. littorea, A. eurynota, $A$. fulvipes, $A$. chaudoiri incognita, $A$. equestris, thermal constants, lower development threshold, sum of effective temperatures, rate isomorphy

\begin{abstract}
Development rates of the eggs of 9 species, larvae of 6 species and pupae of 6 species of the genus Amara (Coleoptera: Carabidae) were recorded at five constant temperatures between 17 and $28^{\circ} \mathrm{C}$, and thermal constants for each development stage calculated. The lower development threshold varied between $9.2-13.5^{\circ} \mathrm{C}$ for different stages and species. Rate isomorphy, which implies the existence of a common temperature threshold for all development stages, was demonstrated in 5 species. The sum of effective temperatures differed between stages. On average the egg stage took 18\%, the first larval instar 13\%, second instar $13 \%$, third instar $35 \%$ and pupa $21 \%$ of the total development time. A poor diet increased the SET of the larvae. The results are compared with published data on Carabidae.
\end{abstract}

\section{INTRODUCTION}

The duration of development is an insect life history trait, shaped by the environments in which the species live. As a consequence relating the variation in development time to geographic or climatic data makes an interesting macroecological study. Important in this context are the differences between closely related taxa. The best characteristics that describe the temperature requirements of a species with direct (non-dormant) development are the thermal constants, lower development threshold (LDT) and sum of effective temperatures (SET). LDT is the temperature at which development ceases, while SET is the number of heat units, day degrees (dd), above the LDT required for complete development. Thermal constants can be calculated assuming a linear relationship between temperature and development rate (reciprocal of development duration). This assumption is realistic for temperatures between 3-4 degrees above LDT and the temperature at which the development is the shortest. In this range of "ecologically relevant temperatures" insects spend most of their active lives (Howe, 1967).

Jarošík et al. (2002) demonstrated that LDT is constrained within a population of a species and does not differ between development stages. A manifestation of this constraint is isomorphy of the development rate, which means that the proportion of development time spent in a particular development stage does not change with temperature. The LDT, however, varies between taxa. A large data set, accumulated over the past 70 years (reviewed by Honěk \& Kocourek, 1990; Honěk, 1996; Kiritani, 1997), reveals large differences between species and probably also between populations of the same species. However, for comparative studies this data should be used with caution. As LDT is a virtual value that is outside the range of ecologically relevant temperatures, its calculation involves an extrapolation of experimental data. This makes the estimation of LDT rather imprecise.
For forecasting development times this lack of precision is not important (Jarošík et al., 2002). This is because the LDT and SET of a stage are intercorrelated. An error in LDT is accompanied by a corresponding and compensating error in SET, when the duration of development is calculated.

However, for comparative studies any error in LDT has serious consequences. The LDT calculated for a species from the literature often varies by several degrees. Different data sets are difficult to compare because of reported or concealed differences in experimental design. The bias is decreased when several species are compared using a uniform method. The variation in LDT values decreases because the experimental "noise" becomes small relative to the true differences between taxa. For the comparison of closely related taxa and/or those from a small area, data collected under identical conditions are indispensable. In contrast to LDT, SET varies between stages depending on a number of factors including food quality and quantity and body size (Honěk, 1999; Honěk et al., 2002).

The constraints and adaptive trends in thermal constants are best studied in groups of related species using an identical design. In this study the thermal constants of nine species of the genus Amara (Coleoptera: Carabidae) were determined. These species commonly occur on arable land where they are important predators of the seeds of weed plants (Thiele, 1977; Saska \& Jarošík, 2001). However, the thermal requirements of carabids are little studied and reliable data are scarce. The data collected was used to test for rate isomorphy of development (Jarošík et al., 2002) and compare the thermal constants of closely related species.

\section{MATERIAL AND METHODS}

Experimental material. The experiments on species of the genus Amara Bonelli were done in 2001 and 2002. Specimens 
of species of the subgenus Amara Bonelli, Amara aenea (De Geer), Amara similata (Gyllenhal), Amara ovata (Fabricius), Amara familiaris (Duftschmid), Amara littorea C.G. Thomson, Amara eurynota (Panzer) and subgenus Percosia Zimmermann, Amara equestris (Duftschmid) were collected at Prague-Ruzynè in the Czech Republic $\left(50^{\circ} 06^{\prime} \mathrm{N}, 14^{\circ} 15^{\prime} \mathrm{E}\right)$. Those of the subgenus Zezea Csiki, Amara fulvipes (Audinet-Serville) and Amara chaudoiri incognita Fassati were collected at Rybník near Levice, Slovakia $\left(48^{\circ} 18^{\prime} \mathrm{N}, 18^{\circ} 34^{\prime} \mathrm{E}\right)$. These beetles were kept in pairs in glass Petri dishes $(10$ or $20 \mathrm{~cm}$ in diameter, 2 or $4 \mathrm{~cm}$ deep, filled to a depth of 1 or $2 \mathrm{~cm}$ with sieved garden soil moistened with tap water. All species were kept at $17.5 \pm 1^{\circ} \mathrm{C}$ and a long-day photoperiod (16L : 8D). Twice a week the beetles were provided with pieces of larvae of Tenebrio molitor Linnaeus (Coleoptera: Tenebrionidae) and a mixture of seeds of herbaceous plants. The quality of the diet influences the rate of oviposition in granivorous species (Saska, unpubl.), therefore the dominant weed species that shed seeds during their respective oviposition periods were chosen as food: Tripleurospermum inodorum (L.) Schultz-Bip. and Artemisia vulgaris L. for Amara eurynota and A. equestris (autumn-breeders) and Stellaria media (L.) Vill. and Capsella bursa-pastoris (L.) Med. for the remaining (spring-breeders) species. To obtain eggs of approximately the same age, the soil was replaced and eggs removed daily.

Experimental temperatures. The duration of development of the egg, larva and pupa were recorded at 17, 19, 22, 25 and $28^{\circ} \mathrm{C}$, which fluctuated at irregular intervals by $\pm 0.7^{\circ} \mathrm{C}$ around these means. These temperatures were considered to be "ecologically relevant temperatures" (Howe, 1967) for all the species. They were achieved at a tempered room $\left(17^{\circ} \mathrm{C}\right)$ and in temperature conditioned boxes (other temperatures). To increase the precision of the temperature measurements, they were recorded at $1 \mathrm{~h}$ intervals, using dataloggers Tinytalk $^{\circledR}$ placed within 10 $\mathrm{cm}$ of an experimental vial and enclosed in the glass container, which experienced conditions similar to those inside the Petri dishes. The average temperature during development of egg, pupa and each of the larval instars was calculated as an arithmetic mean of the logged data. It was calculated separately for each stage of each individual.

Establishing temperature effects. Eggs, 0-24 h old, were placed in glass Petri dishes $(6 \mathrm{~cm}$ in diameter, $1.5 \mathrm{~cm}$ deep) filled to a depth of $0.4-0.5 \mathrm{~cm}$ with plaster of Paris mixed with charcoal. This layer was kept moist by adding daily several drops of tap water, which maintained a suitable humidity but did not cause the growth of moulds. The eggs were examined 3 times a day until they hatched. The larvae were reared individually in Petri dishes $(6 \mathrm{~cm}$ in diameter, $1.5 \mathrm{~cm}$ deep) filled to a depth of $1 \mathrm{~cm}$ with sieved garden soil regularly moistened with drops of tap water. The food was placed on the substrate surface. Larvae of the subgenus Amara were fed with their preferred seeds: C. bursa-pastoris (A. aenea, A. similata, A. ovata, A. littorea) or S. media (A. familiaris) (Saska \& Jarošik, 2001). The larvae of $A$. fulvipes and $A$. chaudoiri incognita were fed pieces of $T$. molitor larvae because their food preferences were unknown but previous results indicated they were carnivorous. Moulting of larvae, pupation, and emergence of adults were checked for daily. The development of larvae and pupae of the "autumn-breeding" species $A$. eurynota and $A$. equestris was not investigated because they were expected to undergo larval dormancy. In species of the subgenus Amara, duration of development of some individuals increased in the third instar because their legs, head capsule or urogomphi were encrusted with dirt and soil particles. This prevented the larvae from moulting and the development time increased. Data for these larvae were not used to calculate thermal constants.

Data processing. The thermal constants were calculated using the duration of development of stages of particular individuals (D) and mean temperatures (T). A linear relationship between development rate (1/D) and temperature $(T): 1 / D=a T$ $+\mathrm{b}$ was established, separately for each stage of development. From this the lower development threshold LDT $\left({ }^{\circ} \mathrm{C}\right)$ was calculated as $-b / a$, and sum of effective temperatures SET (dd) as 1/a. A linear relationship between development rate and mean temperature for each stage of each individual was calculated. That is, the thermal constants were calculated from data for particular individuals. This procedure differs from the usual method of calculating thermal constants, which uses the average development length for all the individuals reared at a particular temperature. We adopted this procedure because of (i) oscillations in the mean temperature around the average "constant" temperature (the average temperature was not the same for all individuals) and because (ii) some individuals were observed for only a part of their development. The variation in the duration of development and thermal constants between stages and species was tested by one-way ANOVA, with the thermal constants as dependent variables and development stage or species as factors. The differences between means were tested using a post-hoc LSD test (Sokal \& Rohlf, 1981). The calculations were done using the commercial statistical program GLIM $^{\circledR} 3.77$. Throughout the paper, means are accompanied by \pm standard errors of mean (SE).

Rate isomorphy. The data for species that completed development were tested for rate isomorphy. Average proportion of the total development time spent in the egg, larval and pupal stages at $17.5,19.7,25.0$ and $27.2^{\circ} \mathrm{C}$ (i.e. average logged temperatures) were calculated. The proportions were plotted against temperature for each stage and species, and regressions of proportions on temperature calculated. The slopes of the regression lines were calculated. Rate isomorphy was tested for using (i) ANOVA, (ii) the slopes of the regressions (Jarošík et al., 2002) and (iii) the slope of the two most different regressions for each species. For the ANOVA, either species or stage was the factor and proportion the dependent variable. Whether the slopes of the regressions differed from zero was tested using t-test: $t=$ slope of regression / SE of the slope (Crawley, 1993). For intraspecific comparison, the two most different regression lines were compared. The differences in proportions against temperature were tested whether the slope of this regression differed from zero using a t-test.

\section{RESULTS}

Thermal constants. The development rate increased proportionally with temperature and is well represented by a linear relationship. Data for all development stages were obtained for six species, $A$. aenea, A. familiaris, $A$. fulvipes (except the third instar), A. littorea, $A$. ovata, $A$. similata (Fig. 1). In A. chaudoiri incognita, A. equestris and $A$. eurynota only the development of the egg (Fig. 2) was investigated. Thermal constants (Table 1) varied between species and stages. The LDT varied between $9.2^{\circ} \mathrm{C}$ (A. similata, second instar larva) and $13.8^{\circ} \mathrm{C}(A$. fulvipes, first instar larva). Mean value $( \pm \mathrm{SE})$ for all stages $(\mathrm{n}=32)$ was $11.1 \pm 0.2^{\circ} \mathrm{C}$. The maximum range in the LDT for a species was $3.2^{\circ} \mathrm{C}$ in $A$. fulvipes, the minimum $1.0^{\circ} \mathrm{C}$ in $A$. ovata. The mean values of the LDTs of the six species, whose complete development 
TABLE 1. Lower development threshold LDT $\left({ }^{\circ} \mathrm{C}\right)$ and sum of effective temperatures SET (day degrees) for egg, larval and pupal stages of nine species.

\begin{tabular}{|c|c|c|c|c|c|c|c|c|c|c|}
\hline \multirow[t]{3}{*}{ Species } & \multirow{2}{*}{\multicolumn{2}{|c|}{ Egg }} & \multicolumn{6}{|c|}{ Larva } & \multirow{2}{*}{\multicolumn{2}{|c|}{ Pupa }} \\
\hline & & & \multicolumn{2}{|c|}{ L1 } & \multicolumn{2}{|c|}{$\mathrm{L} 2$} & \multicolumn{2}{|c|}{$\mathrm{L} 3$} & & \\
\hline & LDT & SET & LDT & SET & LDT & SET & LDT & SET & LDT & SET \\
\hline Amara aenea & 10.4 & 70.9 & 12.4 & 47.7 & 12.2 & 61.6 & 10.9 & 147.1 & 12.6 & 70.5 \\
\hline Amara familiaris & 10.9 & 71.5 & 9.7 & 51.9 & 10.7 & 46.0 & 9.7 & 118.9 & 11.8 & 69.2 \\
\hline Amara similata & 9.3 & 97.2 & 10.3 & 47.9 & 9.2 & 53.4 & 9.5 & 152.9 & 11.0 & 82.5 \\
\hline Amara ovata & 11.4 & 71.6 & 10.8 & 47.4 & 11.8 & 47.2 & 10.9 & 155.6 & 11.4 & 81.8 \\
\hline Amara littorea & 11.7 & 59.9 & 9.8 & 60.8 & 11.0 & 52.1 & 12.1 & 139.7 & 9.9 & 109.1 \\
\hline Amara eurynota ${ }^{1}$ & 13.5 & 110.2 & - & - & - & - & - & - & - & - \\
\hline Amara fulvipes & 12.2 & 56.6 & 13.8 & 54.1 & 10.6 & 100.9 & - & - & 12.0 & 99.9 \\
\hline Amara chaudoiri incognita & 9.8 & 82.7 & - & - & - & - & - & - & - & - \\
\hline Amara equestris $^{1}$ & 12.6 & 114.8 & - & - & - & - & - & - & - & - \\
\hline
\end{tabular}

${ }^{1}$ autumn-breeding species

was monitored (Table 2), differed significantly between species (ANOVA: mean square $\mathrm{MS}=4.82, \mathrm{~F}_{5,23}=3.68, \mathrm{p}$ $=0.014$ ) but not stages within species (ANOVA: $\mathrm{MS}=$
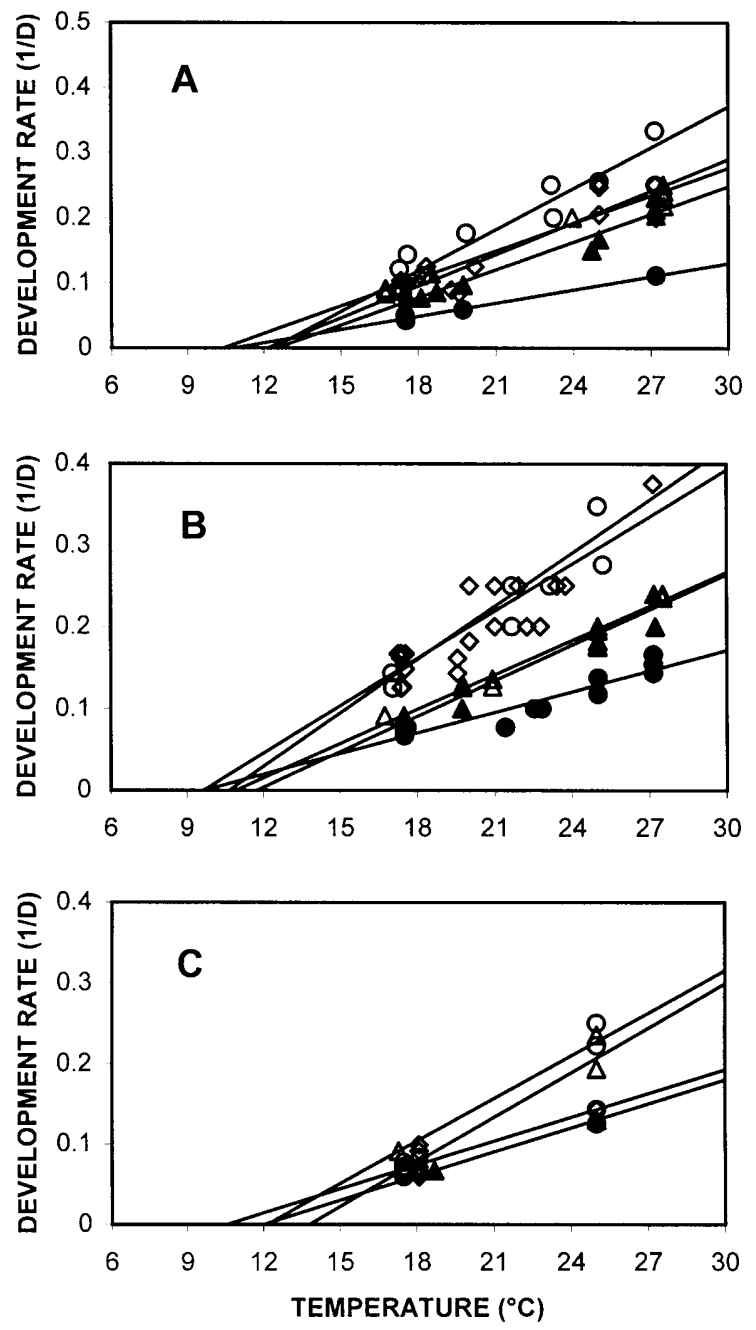

$\left.0.88, \mathrm{~F}_{4,24}=0.42, \mathrm{p}=0.792\right)$. The range in LDT within a stage was between $2.6^{\circ} \mathrm{C}$ in the third instar and $4.2^{\circ} \mathrm{C}$ in the egg (mean $=3.3^{\circ} \mathrm{C}, \mathrm{SD}=0.8, \mathrm{n}=5$ ). However, varia-
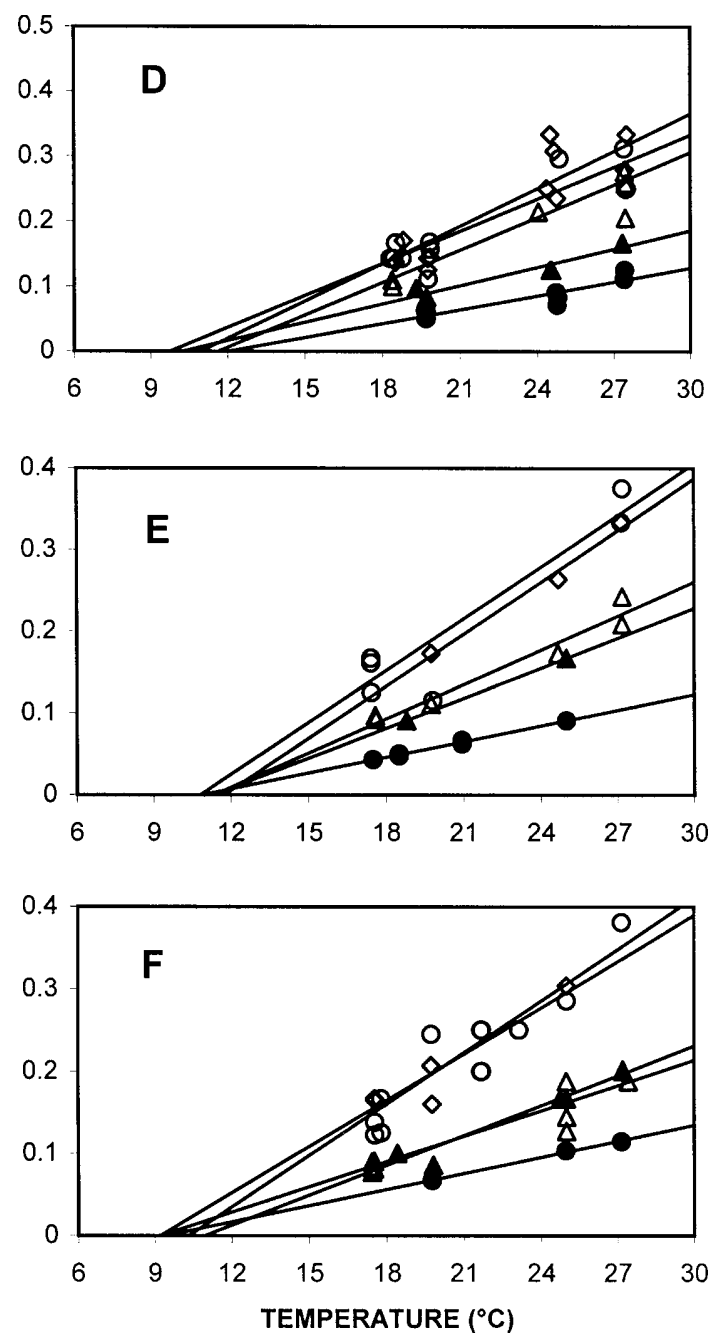

Fig. 1. Linear regression of development rate on temperature for eggs $(\triangle)$, first $(\bigcirc)$, second $(\diamond)$, and third $(\bullet)$ instar larvae and pupae ( $(\mathbf{\Lambda})$ of six species of Amara: $\mathrm{A}-A$. aenea; $B-A$. familiaris; $\mathrm{C}-A$. fulvipes; D - A. littorea; $\mathrm{E}-A$. ovata; $\mathrm{F}-A$. similata. 
TABLE 2. Mean lower development threshold LDT $\left({ }^{\circ} \mathrm{C}\right)$ and sum of effective temperatures SET (day degrees) for particular development stages and species.

\begin{tabular}{lccc}
\hline & $\mathrm{n}$ & $\begin{array}{c}\text { LDT } \\
\text { (mean } \pm \mathrm{SE} \text { ) }\end{array}$ & \multicolumn{1}{c}{$\begin{array}{c}\text { SET } \\
\text { (mean } \pm \mathrm{SE} \text { ) }\end{array}$} \\
\hline Development stage & & & \\
egg - pooled data & 9 & $11.3 \pm 0.5$ & $81.7 \pm 7.1$ \\
egg - spring-breeders & 7 & $10.8 \pm 0.4$ & $72.9 \pm 5.2$ \\
egg - autumn-breeders & 2 & $13.1 \pm 0.5$ & $112.5 \pm 2.3$ \\
first instar & 6 & $11.1 \pm 0.7$ & $51.6 \pm 2.1$ \\
second instar - pooled data & 6 & $10.9 \pm 0.4$ & $60.2 \pm 8.4$ \\
second instar - A. fulvipes & 5 & $11.0 \pm 0.5$ & $52.1 \pm 2.8$ \\
excluded & 5 & $10.6 \pm 0.5$ & $142.8 \pm 6.6$ \\
third instar & 6 & $11.5 \pm 0.4$ & $85.5 \pm 6.5$ \\
pupa & & & \\
Species & 5 & $11.7 \pm 0.4$ & $79.6 \pm 17.4$ \\
Amara aenea & 5 & $10.6 \pm 0.4$ & $71.5 \pm 12.8$ \\
Amara familiaris & 5 & $9.9 \pm 0.3$ & $86.8 \pm 18.9$ \\
Amara similata & 5 & $11.3 \pm 0.2$ & $80.7 \pm 19.9$ \\
Amara ovata & 5 & $10.9 \pm 0.5$ & $83.7 \pm 17,1$ \\
Amara littorea & 4 & $12.2 \pm 0.7$ & $77.9 \pm 13.0$ \\
Amara fulvipes & 29 & $10.9 \pm 0.3$ & $80.2 \pm 6.4$ \\
\hline Average & & & \\
\hline
\end{tabular}

tion in the egg stage decreased when the mean LDT was calculated separately for spring breeding $\left(10.8 \pm 0.4^{\circ} \mathrm{C}\right)$ and autumn breeding species $\left(13.1 \pm 0.5^{\circ} \mathrm{C}\right)$, whose LDTs differed significantly $(\mathrm{t}=2.529, \mathrm{p}<0.01)$.

The SET values (Table 1) differed between stages (MS $\left.=6741.0, \mathrm{~F}_{4,27}=22.76, \mathrm{p}=2.56 \mathrm{E}-08\right)$ but were similar between species $\left(\mathrm{MS}=333.0, \mathrm{~F}_{8,23}=0.24, \mathrm{p}=0.979\right.$ ). Variation within stages was thus lower than within species (Table 2). The SET of the egg stage varied between $56.6 \mathrm{dd}$ (A. fulvipes) and $114.8 \mathrm{dd}$ (A. equestris), and was significantly different for "spring" and "autumn-breeding" species $(\mathrm{t}=3.570, \mathrm{p}<0.01)$. After separating these two groups the variation in SET was smaller (Table $2)$. The variation in SET in the second instar decreased after excluding $A$. fulvipes, whose development was prolonged by the unsuitable diet (Table 2). In species for which data for all stages were available variation within instars was lower $\left(\mathrm{MS}=7001.0, \mathrm{~F}_{4,20}=47.69, \mathrm{p}=\right.$ $5.95 \mathrm{E}-10)$ than within species (MS $=169.9, \mathrm{~F}_{4,20}=0.11, \mathrm{p}$ $=0.978$ ). The multiple paired comparison test revealed that the SET for the first and second larval instars and for

TABLE 3. The differences in the SET for the different development stages of $A$. aenea, A. familiaris, A. similata, A. ovata and $A$. littorea between stages (LSD test: $\mathrm{MS}=7001.0, \mathrm{~F}_{4,20}=$ $47.69, \mathrm{p}<<0.001)$.

\begin{tabular}{lcccccc}
\hline Stage & $\mathrm{n}$ & egg & L1 & L2 & L3 & pupa \\
\hline egg & 5 & 0 & & & & \\
L1 & 5 & NS & 0 & & & \\
L2 & 5 & NS & NS & 0 & & \\
L3 & 5 & $*$ & $*$ & $*$ & 0 & \\
pupa & 5 & NS & $*$ & $*$ & $*$ & 0 \\
\hline
\end{tabular}

NS - not significant; $*$ - significant at $\mathrm{p}<0.05$

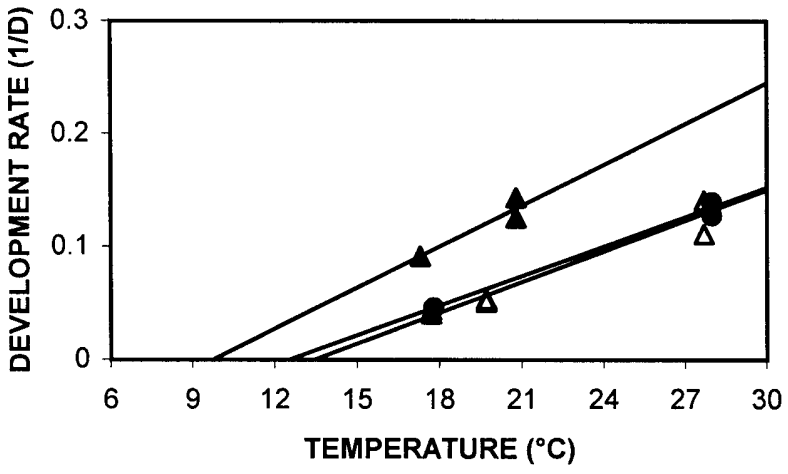

Fig. 2. Linear regression of development rate on temperature for eggs of $A$. chaudoiri incognita $(\mathbf{\Lambda})$, A.equestris $(\bigcirc)$, A. eury$\operatorname{nota}(\triangle)$.

pupae and eggs were similar while that for the third instar differed significantly from all other instars (Table 3 ).

Rate isomorphy. The proportions of time spent in a particular stage (Table 4) varied significantly between stages (ANOVA using data for particular larval instars: $\left.\mathrm{MS}=0.039, \mathrm{~F}_{4,20}=84.16, \mathrm{p}=3.21 \mathrm{E}-12\right)$ but not between species $\left(\mathrm{MS}=6.0 \mathrm{E}-06, \mathrm{~F}_{4,20}=0.001, \mathrm{p}=0.999\right)$. Average proportions of time (mean $\pm \mathrm{SE}$ ) spent in the egg stage, first, second and third larval instar, and pupal stage was $18.2 \pm 1.3 \%, 12.6 \pm 1.0 \%, 13.4 \pm 1.2 \%, 34.5 \pm 1.3 \%$, and $21.4 \pm 0.8 \%$, respectively. The larval stages took $60.4 \pm$ $1.7 \%$ of the total development time. The slopes of the regression lines of proportion on temperature were not significantly different from zero for all stages and species (Fig. 3). Maximum departure from a slope of zero was found for the eggs of $A$. similata $(\mathrm{t}=1.46, \mathrm{p}>0.2)$, the least for the pupae of $A$. aenea $(\mathrm{t}=0.01, \mathrm{p}>0.5)$. The slopes of the regressions for particular development stages were not significantly different in any species. The greatest departure from a slope of zero was observed in $A$. littorea $(\mathrm{t}=0.77, \mathrm{p}>0.5)$.

Food and mortality. Generally, the mortality of eggs, first and second instar larvae was low, except for species of the subgenus Zezea fed on T. molitor larvae. As this unsuitable diet decreased the development rate of the larvae, thermal constants for $A$. chaudoiri incognita (all stages) and $A$. fulvipes (the third instar) were not calculated.

\section{DISCUSSION}

Although Carabidae are well studied the effect of temperature on their development has only been studied in

TABLE 4. Proportions of total development spent in particular stages of development in five Amara species.

\begin{tabular}{lcccccc}
\hline & \multirow{2}{*}{ Egg } & \multicolumn{4}{c}{ Larva } & \multirow{2}{*}{ Pupa } \\
\cline { 3 - 6 } & & L1 & L2 & L3 & Total & \\
\hline Amara aenea & 0.15 & 0.13 & 0.17 & 0.35 & 0.65 & 0.20 \\
Amara familiaris & 0.21 & 0.13 & 0.13 & 0.31 & 0.57 & 0.22 \\
Amara similata & 0.22 & 0.11 & 0.12 & 0.34 & 0.56 & 0.22 \\
Amara ovata & 0.18 & 0.13 & 0.12 & 0.37 & 0.62 & 0.20 \\
Amara littorea & 0.15 & 0.14 & 0.13 & 0.36 & 0.62 & 0.23 \\
\hline
\end{tabular}


A

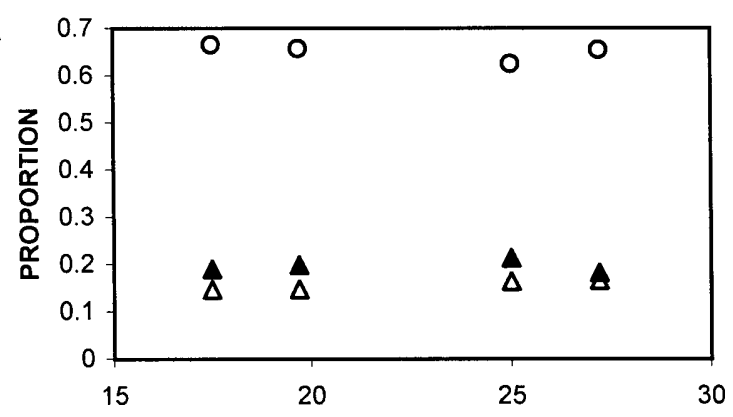

B
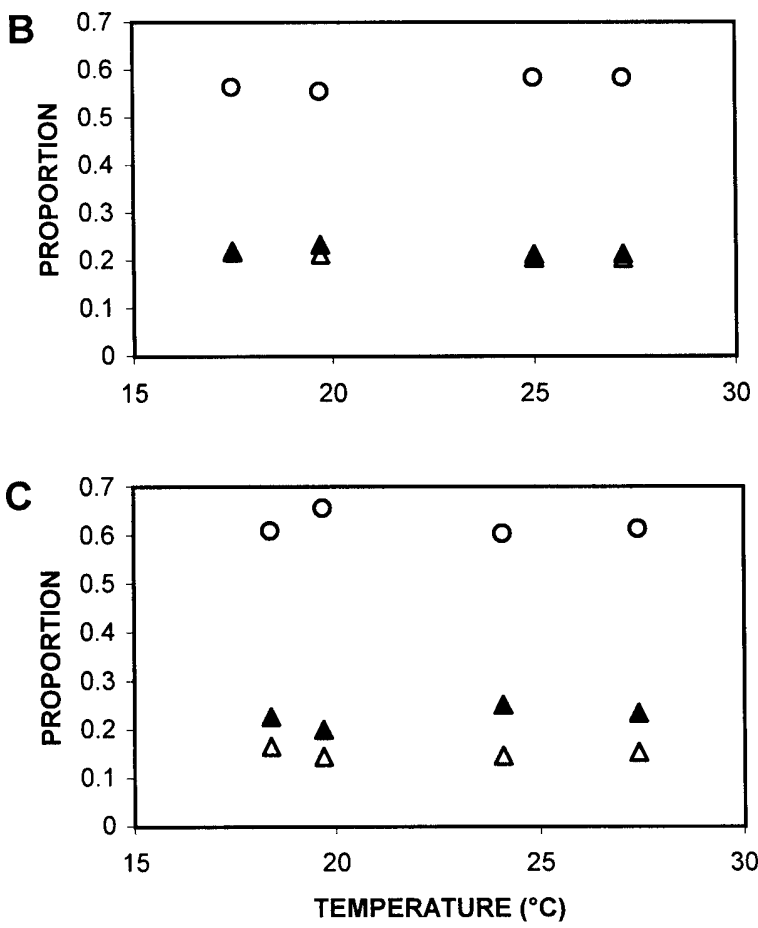

few species (Balachowsky, 1962; Paarmann, 1966; Luff, 1973; Ferenz, 1975; Hůrka, 1975; Luff, 1975; Sota, 1986; Jensen, 1990; Paarmann, 1994; van Dijk, 1994). From this information the thermal constants for at least one stage were estimated in only 11 species (Table 5). Those
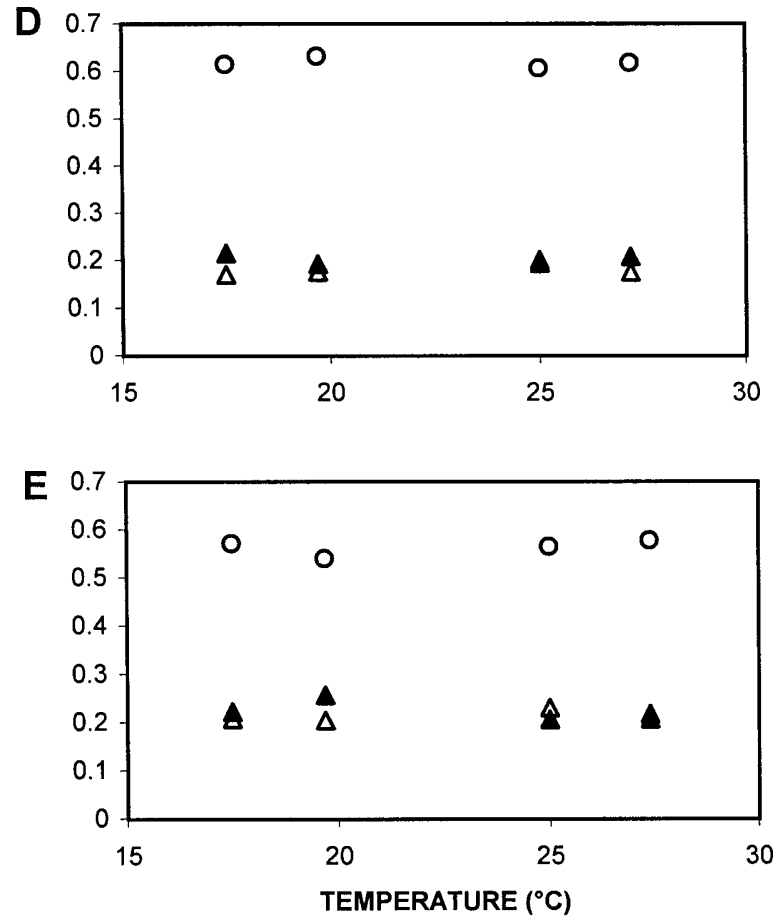

Fig. 3. Proportion of total development time spent in egg $(\triangle)$, larval $(\bigcirc)$ and pupal $(\Delta)$ stages at particular temperatures. The zero slopes of the egression lines indicates rate isomorphy in the five species. A $-A$. aenea; $\mathrm{B}-A$. familiaris; $\mathrm{C}-A$. littorea; D $-A$. ovata; $\mathrm{E}-A$. similata.

for other species are confounded by fluctuating temperature regimes, dormancy or changing food quality. This study doubles the available knowledge by providing data for a further nine species.

TABLE 5. Thermal constants for carabids calculated from data in the literature.

\begin{tabular}{|c|c|c|c|c|c|c|c|c|c|c|c|c|c|}
\hline \multirow{3}{*}{ Species } & \multirow{2}{*}{\multicolumn{2}{|c|}{ Egg }} & \multicolumn{8}{|c|}{ Larva } & \multirow{2}{*}{\multicolumn{2}{|c|}{ Pupa }} & \multirow{3}{*}{ Reference } \\
\hline & & & \multicolumn{2}{|c|}{ L1 } & \multicolumn{2}{|c|}{ L2 } & \multicolumn{2}{|c|}{ L3 } & \multicolumn{2}{|c|}{ Total } & & & \\
\hline & LDT & SET & LDT & SET & LDT & SET & LDT & SET & LDT & SET & LDT & SET & \\
\hline Zabrus tenebrionoides (Goeze) & 12.9 & 118.3 & & & & & & & & & & & Balachowsky, 1962 \\
\hline Pterostichus quadrifoveolatus Letzner & 9.7 & 77.8 & 10.7 & 90.8 & 10.0 & 92.1 & 7.6 & 210.0 & & & 8.6 & 102.9 & Paarmann, 1966 \\
\hline Pterostichus oblongopunctatus (Fabricius) & 8.6 & 88.1 & 5.8 & 104.1 & & & & & & & 8.0 & 103.4 & Paarmann, 1966 \\
\hline Pterostichus madidus (Fabricius) & 2.0 & 285.1 & & & & & 1.9 & 1819.0 & & & 1.6 & 235.6 & Luff, 1973 \\
\hline Pterostichus nigrita (Paykull) ${ }^{1}$ & & & & & & & & & $6.7^{3}$ & $419.7^{3}$ & & & Ferenz, 1975 \\
\hline Pterostichus nigrita (Paykull) ${ }^{2}$ & & & & & & & & & $6.5^{3}$ & $375.5^{3}$ & & & Ferenz, 1975 \\
\hline Pterostichus melanarius (Illiger) & & & & & & & & & & & 7.9 & 139.9 & Hůrka, 1975 \\
\hline Nebria brevicollis (Fabricius) & & & & & & & & & & & 4.0 & 129.9 & Luff, 1975 \\
\hline Carabus yaconimus Bates & 5.6 & 151.1 & & & & & & & 1.5 & 597.5 & 5.7 & 157.3 & Sota, 1986 \\
\hline Bembidion lampros (Herbst) & 9.5 & 93.2 & & & & & & & 6.1 & 340.9 & 7.2 & 113.7 & Jensen, 1990 \\
\hline Pterostichus adstrictus Escholtz & 5.5 & 119.4 & 6.6 & 81.5 & & & & & & & 7.8 & 97.1 & Paarmann, 1994 \\
\hline Poecilus versicolor $(\text { Sturm })^{4}$ & & & & & & & & & 8.5 & 411.0 & 5.5 & 135.9 & van Dijk, 1994 \\
\hline Poecilus versicolor $(\text { Sturm })^{5}$ & & & & & & & & & 7.6 & 358.8 & 4.8 & 133.7 & van Dijk, 1994 \\
\hline
\end{tabular}

${ }^{1}$ Germany; ${ }^{2}$ Sweden; ${ }^{3}$ constants for total development of larva and pupa; ${ }^{4}$ low food supply; ${ }^{5}$ high food supply. 
The range in the LDTs calculated for Amara species was $9.2-13.8^{\circ} \mathrm{C}$ (Table 1). With the exception of the eggs of Zabrus tenebrionoides (Goeze) (Balachowsky, 1962) Pterostichus quadrifoveolatus Letzner (Paarmann, 1966) and Bembidion lampros (Herbst) (Jensen, 1990), and the first and second instars of P. quadrifoveolatus (Paarmann, 1966), the previous studies resulted in LDTs that were lower than those recorded for Amara species in this study (Table 5).

The variation in the LDT of the different stages of Amara species was smaller than that recorded in Carabus yaconinus Bates (Sota, 1986) or Bembidion lampros (Jensen, 1990) but similar to that in P. quadrifoveolatus (Paarmann, 1966). The test for rate isomorphy detected five species for which the assumption of an identical LDT for all the species could not be rejected. The test indicated that the intraspecific variation in the LDT of the different stages of these species $\left(1.0-2.3^{\circ} \mathrm{C}\right)$ resulted from an experimental bias in the data. This supports the prediction of Jarošík et al. (2002). However, the distribution of rate isomorphy in taxa, which have different life cycles (Danks, 1987) or show temperature acclimation (Precht et al., 1973), requires further study.

Low interspecific variation in the LDT of Amara species (although significant) is consistent with the assumption that the development threshold of taxonomically related species may be constrained (Dixon et al., 1997). However the species with similar LDTs are all spring breeders. To determine the effect of life history spring and autumn breeding species were compared. For Amara species the thermal constants of the egg stage of both groups differed. In autumn breeding species the LDT is higher and the SET greater than in spring breeders. One might expect an opposite trend since low LDT would facilitate egg development in the cool weather of autumn. Thus in larvae of $C$. yaconinus the low LDT could be an adaptation to low temperatures (Sota, 1986). An example of this type of adaptation is seen in the autumn breeding neuropteran genus Micromus (Hemerobiidae) (Szentkira1yi, 1986). In Central Europe, the LDT for egg development in this genus is significantly lower $\left(7.3 \pm 1.1^{\circ} \mathrm{C}\right)$ than in spring and summer breeding species of the family Chrysopidae $\left(9.3 \pm 0.3^{\circ} \mathrm{C}\right)$ (Honěk \& Kocourek, 1988). However, the opposite trend in Amara species may have an ecological significance. This is supported by the existence of a high LDT and SET in another autumn-breeding species, Z. tenebrionoides (Balachowsky, 1962). High thermal requirements for egg development may postpone the hatching of eggs deposited during a warm period in late summer. The delay in hatching results in timing of larval development occurring just before the overwintering period when the third instar larvae enter an obligatory diapause.

The first and second instars of all five species fed the same suitable diet had similar development times (and SET), whereas that of the third instar was 2-3 times longer. This distribution of development times between larval instars is typical of carabid species whose larvae develop without dormancy (Hůrka, 1988). The proportion of the total development time spent in a particular stage (Table 4) is near to the average values established for Coleoptera, that is, $18 \%$ for egg and $20 \%$ for pupal stages (Honěk \& Kocourek, 1990).

The development rate of Amara species fed a poor diet is decreased slightly in the first instar, and more so in the second and third instars (Saska \& Jarošík, 2001). In this study the development rate of $A$. fulvipes and $A$. chaudoir incognita progressively decreased from the second instar onwards. The marked effect of food quality on development rate (and SET) is typical for phytophagous species (e.g. Honěk et al., 2002). In contrast, in the carnivorous Poecilus versicolor (Sturm) (Table 5) the effect of food on SET is small (van Dijk, 1994).

ACKNOWLEDGEMENTS. The work of P.S. was supported by project No. QD 1350 of the Ministry of Agriculture of the Czech Republic, that of A.H. by project No M 01-01-03 of the Ministry of Agriculture of the Czech Republic. We thank Ing. Z. Martinková for help with the monitoring of experiments.

\section{REFERENCES}

BAlachowsky A.S. 1962: Entomologie Appliquée à l'Agriculture. Tome I-Coléoptères, Premier Volume. Masson, Paris, $564 \mathrm{pp}$.

CRAWLEY M.J. 1993: GLIM for Ecologists. Blackwell, Oxford, $379 \mathrm{pp}$.

DANKS H.K. 1987: Insect Dormancy: an Ecological Perspective. Biological Survey of Canada, Ottawa, $439 \mathrm{pp}$.

Dixon A.F.G., Hemptinne J.L. \& Kindlmann P. 1997: Effectiveness of ladybirds as biological control agents: patterns and processes. Entomophaga 42: 71-83.

Ferenz H.-J. 1975: Anpassungen von Pterostichus nigrita F. (Col.: Carab.) an subarktische Bedingungen. Oecologia 19: $49-57$

HoNĚK A. 1996: Geographical variation in thermal requirements for insect development. Eur. J. Entomol. 93: 303-312.

HoNĚK A. 1999: Constraints on thermal requirements for insect development. Entomol. Sci. 2: 615-621.

Honék A., Jarošík V., Martinková Z. \& Novák I. 2002: Food induced variation of thermal constants of development and growth of Autographa gamma (Lepidoptera: Noctuidae) larvae. Eur. J. Entomol. 99: 241-252.

HoNÉK A. \& KocOUREK F. 1988: Thermal requirements for development of aphidophagous Coccinellidae (Coleoptera), Chrysopidae, Hemerobiidae (Neuroptera), and Syrphidae (Diptera): some general trends. Oecologia 76: 455-460.

HonĚK A. \& KocourReK F. 1990: Temperature and development time in insects: a general relationship between thermal constants. Zool. Jb. Syst. 117: 401-439.

Howe R.W. 1967: Temperature effects on embryonic development in insects. Annu. Rev. Entomol. 12: 15-42.

HƯRKA K. 1975: Laboratory studies on the life cycle of Pterostichus melanarius (Illig.) (Coleoptera: Carabidae). Věst. Čskoslov. Spol. Zool. 39: 265-274.

HƯRKA K. 1988: Reproduction and Development of Ground Beetles (Coleoptera: Carabidae). Unpubl. Dr.Sc. Thesis, Charles Univ., Acad. Sci., Prague. [in Czech]

JARošík V., HonĚK A. \& Dixon A.F.G. 2002: Developmental rate isomorphy in insect and mites. Am. Nat. 160: 497-510.

JENSEN L.B. 1990: Effect of temperature on the development of the immature stages of Bembidion lampros [Coleoptera: Carabidae]. Entomophaga 35: 277-281. 
KiRITANI K. 1997: The low development threshold temperature and the thermal constant in insects, mites and nematodes in Japan. Misc. Publ. Nat. Inst. Agro-Environ. Sci. 21: 1-72.

LUFF M.L. 1973: The annual activity pattern and life cycle of Pterostichus madidus (F.) (Col.: Carabidae). Entomol. Scand. 4: 259-273.

LuFF M.L. 1975: Notes on the biology of the developmental stages of Nebria brevicollis (F.) (Col.: Carabidae) and on their parasites, Phaenoserphus spp. (Hym.: Proctotrupidae). Entomol. Monthly Mag. 111: 249-255.

PAarmann W. 1966: Vergleichende Untersuchungen über die Bindung zweier Carabidenarten (Pterostichus angustatus Dft. und Pterostichus oblongopunctatus F.) an ihre verschiedenen Lebensräume. Z. Wiss. Zool. 174: 83-176.

PAARMANN W. 1994: Temperature and photoperiodic influence on development stages and adults of the subarctic carabid beetle Pterostichus adstrictus (Coleoptera). In: Desender K., Dufrêne M., Loreau M., Luff M.L. and Maelfait J.-P. (eds): Carabid Beetles: Ecology and Evolution. Kluwer, Dordrecht, pp. 201-205.
Precht H., Christophersen J., Hensel H. \& Larcher W. 1973: Temperature and Life. Springer-Verlag, Berlin, $779 \mathrm{pp}$.

SASKA P. \& JAROŠíK V. 2001: Laboratory study of larval food requirements in nine species of Amara (Coleoptera: Carabidae). Plant Protect. Sci. 31: 103-110.

SoKal R.R. \& RohlF F.J. 1981: Biometry. W.H. Freeman, San Francisco, $859 \mathrm{pp}$.

SotA T. 1986: Effects of temperature and photoperiod on the larval development and gonad maturation of a carabid beetle, Carabus yaconinus (Coleoptera: Carabidae). Appl. Entomol. Zool. 21: 89-94.

SZENTKIRÁLYI F. 1986: Niche segregation between chrysopid and hemerobiid subguilds. In: Hodek I. (ed.): Ecology of Aphidophaga 2. Academia, Praha, pp. 297-302.

THIELE H.U. 1977: Carabid Beetles in their Environment. Springer-Verlag, Berlin, $369 \mathrm{pp}$.

VAN DIrK T.S. 1994: On the relationship between food, reproduction and survival of two carabid beetles: Calathus melanocephalus and Pterostichus versicolor. Ecol. Entomol. 19: 263-270.

Received January 27, 2003; revised June 18, 2003; accepted July 14, 2003 